\title{
REFORMAS EDUCACIONAIS EM MINAS GERAIS: INSTRUÇÃO PRIMÁRIA, MODERNIDADE E PROGRESSO (1906-1928)
}

\author{
Luciana Beatriz de Oliveira Bar de Carvalho ${ }^{1}$ \\ Universidade de Uberaba (UNIUBE)
}

\section{RESUMO}

Este artigo tem por finalidade analisar a trajetória das reformas educacionais promovidas em Minas Gerais, entre 1906 (Reforma João Pinheiro) a 1928 (Reforma Francisco Campos). O objetivo das Reformas eram difundir a escola primária no estado, bem como visualizar e possibilitar o controle social, fundamental à formação da "cidadania controlada", ou seja, dentro do ideário das elites republicanas. Portanto, compreender o significado delas é entender o sentido dos grupos escolares à época como escolas da "República para a República", que pudessem contribuir para "processo civilizatório" da sociedade mineira, pois sua "missão" era criar/recriar novos sujeitos para o contexto social urbano, principalmente no âmbito da escola primária, portadora de novos conteúdos, métodos de ensino e práticas pedagógicas, que emergiram a partir dessas reformas educacionais.

Palavras-Chave: Reformas Educacionais. Minas Gerais. Educação. Modernidade.

\section{EDUCATIONAL REFORMS IN MINAS: PRIMARY EDUCATION, AND MODERN PROGRESS (1906-1928).}

\begin{abstract}
This article aims to analyze the trajectory of educational reforms promoted in Minas Gerais, between 1906 (Reform João Pinheiro) to 1928 (Reform Francisco Campos). The aim of the reforms were spread in the state primary school, as well as view and enable social control, fundamental to the formation of "citizen control", ie, within the ideology of republican elites. Therefore, understanding their meaning is to make sense of the school groups such as schools at the time of the "Republic to the Republic", which could contribute to "civilizing process" of the mining company, for his "mission" was to create / recreate new individuals to urban social context, especially within the primary school, the bearer of new content, teaching methods and teaching practices, which emerged from these educational reforms.
\end{abstract}

Keywords: Educational Reforms. Minas Gerais. Education. Modernity.

\section{Introdução}

As transformações na sociedade brasileira já se processavam com mais dinâmica desde a segunda metade do século XIX. A própria educação tomava novos rumos: escolas ligadas aos protestantes introduziam a pedagogia dos Estados Unidos, reformas na educação paulista solidificavam a Escola Normal, e à influência positivista se alinhavam tentativas de se pensar no processo educativo com mais clareza e praticidade. A última reforma educacional do Império se preocupou com as necessidades motivadas pelos novos tempos. Embora o parecer de Rui Barbosa — diriam seus detratores — se aproximasse mais de uma obra literária (no sentido da ficção) do que de um projeto concretizável de fato, ele estudara "[...] a estatística e situação do ensino popular; a ação do Estado 
(Ministério da Instrução Pública); despesas com o ensino público, sua incomparável fecundidade; da obrigação escolar; da escola leiga; liberdade de ensino; métodos e programas escolares"2.

$\mathrm{Na}$ educação, elemento suscetível de alavancar mudanças, contribuir para uma revolução no pensamento pedagógico e fundamentar ideologicamente as lutas pela expansão do ensino, destacou-se a Escola Nova: “[...] movimento que reuniu personalidades de diversas tendências, unidas sob a maneira comum de colocar a educação a serviço da cidadania". ${ }^{3}$ Na primeira metade da década de 1920 — início da desintegração do regime oligárquico e marco simbólico de diversas tentativas de se reformar o sistema nacional de ensino - educadores e intelectuais em geral preocupados com a educação brasileira pensavam em fundar uma federação de associações de ensino e até em criar um partido político - a Ação Nacional. Se naquele instante tais ações e manobras políticas foram em vão, os ideais escolanovistas - aqui muito mais ligados aos aspectos técnicos da educação do que à educação popular propriamente dita - continuavam a dar o tom entre os que refletiam sobre a educação. A Escola Nova, que "[...] começa de forma fracionada nos Estados, onde alguns dos seus futuros dirigentes chegaram a assumir posições de destaque na Administração, aos poucos e depois das tentativas acima citadas, no Rio de Janeiro, adquire feição estruturada, em torno da ABE [Associação Brasileira de Educação]", 4 buscando "[...] promover no Brasil a difusão e o aperfeiçoamento da educação em todos os ramos e cooperarem com todas as iniciativas que tendam, direta ou indiretamente, a esse objetivo". 5

Os fundadores da ABE buscaram na National Education Association dos Estados Unidos o modelo de instituição que tivesse, em cada estado, um departamento independente do carioca e viesse, em conjunto, formar um

[...] órgão legítimo de opinião das classes cultas, prontas a colaborar em perfeita harmonia com os governos e aplaudir-lhes os acertos, mas capazes de falar-lhes de frente, de apontar-lhes quando necessário os erros e as lacunas de suas leis de educação e de ensino e de defender vigorosamente, neste terreno, os grandes interesses do Brasil. ${ }^{6}$

Embora o papel da ABE tenha sido significativo na luta pró-transformações na educação brasileira e mesmo com a autoimagem de instituição apolítica - talvez pela necessidade de "[...] escapar à repressão política do governo Bernardes" — — havia contradições em sua atuação. Internamente, ela padecia de um conselho diretor eivado de resíduos positivistas e de alguns membros que eram, por exemplo, diretores do Club dos Bandeirantes do Brasil, “[...] organização de caráter tendencialmente fascista e nitidamente belicista". ${ }^{8}$ Um grupo ligado ao seu conselho participou da organização partidária do Partido Democrático do Distrito Federal, fundado em 1927 - aliás, “[...] o privilégio conferido à educação pelo Partido fez com que este surgisse como espécie de prolongamento da Associação". "Externamente, as influências vinham das disputas ideológicas de então, aqui e no contexto internacional, em que as chamadas democracias capitalistas ocidentais disputavam a hegemonia política e econômica mundial com as ideias totalitárias do fascismo italiano e com o socialismo, implantado na Rússia por Lênin (no Brasil, o Partido Comunista surgiu em 1922). Por consequência, as discussões e os embates políticos eram intensos no interior da associação.

Além da situação contraditória interna, havia outras instituições que não se coadunavam com a ABE: uma, a Sociedade Paulista de Educação, antecessora e nem sempre parceira da associação; outra, a Federação Nacional das Sociedades de Educação, fundada em 1929 sem o apoio da ABE. Se essas contradições internas podem ser vistas 
como motivo para a falta de convergência entre essas instituições, cremos que outra motivação era a imagem que as elites ou mesmo os intelectuais cujo pensamento e interesse se traduziam nos ideais da ABE tinham do povo brasileiro: gente degenerada, endêmica, viciosa. Ora,

[...] a chamada obra educacional da ABE tinha como denominador comum o empenho na moralização dos costumes, proposta como obra de civismo: pregações; festas pedagógicas; controle do lazer por procedimentos vários, que abrangiam a seleção e a censura de filmes, a elaboração de listas de livros recomendáveis e a organização de divertimentos infantis; constituição de Círculos de Pais destinados a alargar o raio de ação formativa da escola etc. [...] Somente a Seção de Ensino Técnico e Superior, em que estava sediado o grupo Labouriau, é que se diferenciava nitidamente desse tipo de intervenção cultural, promovendo cursos e conferências de "alta cultura" para realizar uma "demonstração prática" da viabilidade do ensino universitário no país. [...] À exceção das Conferências Nacionais e dos inquéritos sobre o ensino secundário e superior, o trabalho de estudos e debates ficou limitado às conferências e palestras que a Associação promoveu na cidade do Rio de Janeiro, com intensidade considerável nos anos de 1927 e 1928, sem dúvida, os anos em que a ABE gozou de maior prestígio na década. ${ }^{10}$

Personificada na personagem Jeca Tatu, ${ }^{11}$ essa imagem do brasileiro sintetizava determinismos cientificistas de ordem vária. Ao mesmo tempo em que se lastimava tal realidade determinista, almejava-se superar o estereótipo que o trabalhador brasileiro carregava como ser improdutivo. Essa tarefa caberia à educação: condição natural para eliminar o determinismo social em que a sociedade se encontrava e lhe possibilitar a assimilação de elementos capazes de alterar o meio em que estava, ou seja, o ambiente sociocultural marcado pela ignorância — provam-na os índices de analfabetismo. ${ }^{12}$ Eis por que o entusiasmo pela educação em setores da ABE se resumia, fundamentalmente, à saúde, à moral e ao trabalho: pilares sobre os quais se assentava a convicção relativa à importância da educação. ${ }^{13}$ É nesse clima que surgiram obras como as de Carneiro Leão, José Augusto, Afrânio Peixoto e outras dispostas a refletir sobre a educação brasileira e que o governo federal buscou participar da luta contra o analfabetismo. Afinal, "[...] como esperar o progresso, se o progresso de um povo depende antes de tudo, do amor a instrucção?". "Reflexo disso foi a reforma de João Luiz Alves, em 1925, caracterizada pela "[...] implantação do regime seriado, reorganização do ensino superior". ${ }^{15}$ Também parte desse afã mudancista foram as reformas estaduais de ensino, instrumentos dinamizadores do processo educacional proeminentes em estados como Minas Gerais.

\section{Reforma João Pinheiro: grupo escolar e modernidade pedagógica}

Algo fundamental à educação da massa trabalhadora — base da produção - era um sistema de instrução que a capacitasse: ela precisava ser produtiva, e isso exigia qualificá-la, adequá-la às necessidades dos novos tempos. Essa era a suposição do empresário João Pinheiro, ${ }^{16}$ que deixa entrever três questões significativas: o conceito elitista, determinista e partilhado por intelectuais - de massa popular, a ideia de produtividade fabril aplicada à educação primária e a formação de quem conduziria a missão da escola, tida como sacerdotal 
A noção de massa popular supunha ignorância, que a educação devia anular, civilizando-a e preparando-a para a modernidade; a educação conduziria e orientaria as transformações sociais, econômicas e políticas, isto é, "Reinventar[ia] os sujeitos sociais, sendo a escola afirmada como local legítimo de transmissão do saber considerado como necessário ao cidadão republicano. ${ }^{17}$ Nessa lógica, à República coube, então, materializar as representações da educação escolar como fundamental, visto que eram antigos os vícios que ela tinha de anular de uma vez por todas. Isso supunha "regenerar" a sociedade, sobretudo crianças pobres, para que não se impregnassem desde cedo dos males supostamente disseminados nas populações pobres. ${ }^{18}$ Haveria uma revolução nos costumes do ponto de vista moral em benefício da vida econômica, pois, em vez "[...] de um exército de analfabetos a povoarem as oficinas, [haveria] um pessoal operário suficientemente preparado para exercitar os seus misteres com inteligência e aptidão [...] [apto a dar] garantias de economia e incremento" à indústria que se organizava em Minas. ${ }^{19}$.

Aplicar a ideia de produtividade fabril à educação primária era introduzir o taylorismo na escola, isto é, organizá-la como se organizava o trabalho nos Estados Unidos. Assim, o programa de ensino que começava a ser posto em prática objetivava produzir alunos aptos à leitura e escrita - ou seja, capazes de pensar; a confiar em seu esforço e no valor da disciplina a fim de que adquirissem conhecimentos e soubessem usálos para o êxito e aperfeiçoamento material e moral. ${ }^{20}$ Destinada à massa, a escola primária seria para "[...] os operários não somente uma fonte de luz e alegria, mas uma fonte de proveitos pecuniários". ${ }^{21}$ Por outro lado, em seu universo de atribuições e no cumprimento de sua função,

A escola impõe às crianças uma "oposição e ruptura com relação a seu espaço cotidiano de vida, a sua forma habitual de estar, falar, mover-se e atuar", e como alunos são "submetidos a toda uma ginástica contínua que lhes é estranha: saudar com deferência ao professor, sentar-se corretamente, permanecer em silêncio e imóveis, falar baixo e depois de havê-lo solicitado, levantar-se e sair ordenadamente". Alunos devem ser transformados em bons trabalhadores, e a "maquinaria escolar" como os autores sintetizam a organização da escola, seria a bigorna sobre a qual o professor depositará estas naturezas de ferro para forjar com paciência e obstinação o futuro exército do trabalho. ${ }^{22}$

Enfim, a formação de quem conduziria a missão da educação se esbarrava em seu financiamento. Minas não estava isenta de problemas financeiros nem João Pinheiro ignorava isso. Mas, como o professor da escola pública era tido como essencial ao êxito dos propósitos desse reformador, a solução seria fazer esse professor se conscientizar da importância de sua posição social como braço forte da educação do povo. Ora, "A reforma não podia consentir que o professor continuasse a exercer o papel de roda morta na máquina administrativa, indiferente à causa do ensino e preocupado apenas com a sua situação pessoal". ${ }^{23}$

A implantação dos princípios básicos da reforma em 1906 visava, sobretudo, desenvolver a educação popular num aspecto tríplice: físico, intelectual e moral. ${ }^{24}$ Nesse caso, a reforma buscou organizar pedagogicamente a escola segundo regras e modelos para os prédios escolares e o fornecimento de mobiliário e material didático; também criou a instrução manual, pois era fundamental a um povo civilizado que a escola primária se detivesse não só na instrução abstrata, mas também na educação física e moral do homem. "Daí o natural desenvolvimento que vão tendo os métodos de programas de ensino, acrescidos da ginástica, exercícios físicos e evoluções militares; dos trabalhos manuais; 
canto coral; noções elementares de ciências físicas e naturais; de agronomia, etc." ${ }^{25}$ Os reformadores não se restringiram ao puramente ideológico e teórico; ao contrário, à instrução-educação, acrescentaram uma meta prática voltada à política de desenvolvimento estatal, em que o verdadeiro intuito das escolas segundo métodos da democracia eram "[...] instrução, educação e profissão". ${ }^{26}$

Isso, porém, pedia uma estrutura administrativa que cumprisse a lei. Assim,

Um sistema rigoroso de inspeção escolar foi estabelecido e denominado como "a alma do ensino", e o Estado de Minas Gerais foi dividido em quarenta circunscrições, que seriam percorridas pelos inspetores, agentes de confiança do Governo. A tarefa desses inspetores (todos do sexo masculino) seria a de fiscalizar as escolas e orientar os métodos de ensino e o material pedagógico, com vistas a "abrir aos professores uma maior assistência" em suas condições de trabalho. ${ }^{27}$

A reforma continha pilares que merecem atenção. Por causa dos parcos recursos estatais, um dos pilares era a recorrência à iniciativa particular, cujo estímulo era visto como importante para combater a ignorância e o analfabetismo: chagas que levavam a uma condição "[...] de inferioridade vergonhosíssima em face de outros países. O Estado estava diante de uma magna obra de patriotismo". ${ }^{28}$ Isso significava que o ensino primário podia ser "[...] livremente ministrado no Estado por particulares e associações", os quais se sujeitariam à fiscalização do governo só nos quesitos higiene, moralidade e estatística; também podia continuar a ser "[...] em domicílio particular, por imediata iniciativa das famílias", com estímulo do Estado, que daria aos docentes uma gratificação para cada aluno aprovado no exame final do curso primário oficial. ${ }^{29}$

Outro pilar foi a construção dos grupos escolares segundo o modelo paulista de 1892 sem deixar de lado as escolas isoladas ou agrupadas. Nesse modelo, o grupo escolar condensava a pretendida modernidade pedagógica, e o método intuitivo era central na institucionalização de um sistema de educação pública modelar. ${ }^{30}$ Pretendia-se que os grupos escolares se expandissem, se generalizassem e se consolidassem no estado, a começar na capital, como espaços específicos da instrução educacional de crianças; desse modo, a escola isolada se tornava uma exceção condenada a virar regra. ${ }^{31}$

Se esse pilar suscita inovação física do espaço onde haveria atividades educacionais, também sugere uma posição eminentemente técnica e duas propostas transformadoras: metodologia e ensino seriado.

Ensino seriado, classes homogêneas e reunidas em um mesmo prédio, sob única direção, métodos pedagógicos modernos dados a ver na Escola Modelo anexa à Escola Normal e monumentalidade dos edifícios em que a Instrução Pública se faz signo do Progresso - essa era a fórmula do sucesso republicano em São Paulo. Viagens de estudo a esse Estado e empréstimo de técnicos passam a ser a rotina administrativa na hierarquia das providências com que os responsáveis pela Instrução Pública dos outros Estados (e também do Distrito Federal) tomam iniciativas de remodelação escolar na Primeira República. ${ }^{32}$

Nessa afirmação social da escola, os reformistas optaram pela formação docente; mais que isso, a lei 439, de 28/9/1906, que reorganizava o sistema de instrução pública, criou "[...] a Escola Normal da Capital, destinada exclusivamente ao sexo feminino".33 Vemos essa preferência pela admissão de professoras para o ensino primário de dois modos: como outro pilar da reforma e como justificativa para abrir à mulher mineira uma 
carreira digna que lhe proporcionasse o ensejo para ser útil ao país. ${ }^{34}$ No pensamento pedagógico dos reformadores, a mulher compreenderia mais a infância, logo a professora estaria apta a educar sem "desviar" o espírito, sem "corromper" o coração e sem "degradar" o caráter. "Acresce que a professora com mais facilidade sujeita-se aos vencimentos com que o Estado pode remunerar o seu professorado." ${ }^{35}$ Essa feminização da docência tinha suas razões de ser: uma era afetiva - a docilidade e o caráter da mulher, tidos como essenciais à educação de crianças; outra era de fundo social e moderno estimular abertura do mercado de trabalho à mulher; a terceira era econômica - o Estado não podia pagar bons salários, mas a mulher podia se submeter a essa condição. Eis a visão sacerdotal do magistério: trabalho feito por abnegação, por "amor" à causa. Eis o mito do sacrifício: dedicação sem pecúnia. Não nos esqueçamos, porém, de que essa mulher que ganhou espaço num trabalho útil e digno era de classe social abastada, por isso o salário era secundário.

Por fim, o quarto pilar da reforma seria a ideia de produtividade, que se soma à "[...] freqüência mínima, para manutenção de uma escola primária, a qual seria de 20 alunos por turma". ${ }^{36}$ Quando a exigência, estabelecida por lei, não era atendida, o governo fechava a escola - e de fato cerca de 300 foram fechadas. Nesse caso, o gasto se condicionava à produtividade. É claro, essa atitude foi criticada severamente; houve até quem suspeitasse de que o fechamento tivesse motivação política - o governo negava a suspeita.

Embora o povo não tenha aderido à suposição - elitista - de que a escola tinha de mudar para se compatibilizar com a modernidade, isto é, civilizar a população pobre, a reforma de 1906 pretendeu expandir o ensino: fazê-lo chegar a todas as faixas da população, mas sem determinar radicalmente a obrigatoriedade do ensino. Ainda assim, a edição de 14 de março de 1909 do jornal O progresso, de Uberabinha, publicou o texto "A obrigatoriedade do ensino", que cobrava tal atitude do governo:

Três anos após a reforma, em 1909, outro Secretário do Interior, Estevão Leite de Magalhães Pinto, ${ }^{37}$ fez um balanço do que fora conseguido até então, avaliando que podia-se sentir "uma nova vida transpirar das escolas, ontem tristes e sem alento", mostrando-se ufanista ao comentar o que esperava do novo programa escolar, que deveria "instruir sem fatigar e deleitando", provocando, assim, "o amor da criança pela escola". 38

Afora essas questões relativas aos grupos escolares, em meados da década de 1920 já havia uma efervescência ideológica favorável à regulamentação educacional em Minas, mas sua implantação foi obstada pela desintegração gradativa do poder oligárquico, com vários conflitos nos grupos dominantes. Por outro lado, havia uma classe média se expandindo, um operariado crescendo e o êxodo rural começando - e, com este, o excesso na oferta de trabalho. Era preciso redefinir a aliança dos políticos mineiros com outras oligarquias estaduais, sobretudo as de São Paulo, e no interior de Minas. Era o pósguerra, o Brasil mudava, e a aproximação da modernidade exigia novos instrumentos de convivência social.

Uma vez que a educação foi eleita instrumento para preparar a população, a reforma educacional era premente. Sem demora, em 1924, o governo mineiro de Fernando Mello Vianna começou a publicar seu regulamento do ensino primário, posto em prática a partir de janeiro de 1925 para reformar a instrução pública. Viana fora secretário do Interior no governo de Raul Soares de Moura, que foi eleito para governar de 1922 a 1926, mas morreu em 1924. Seu vice, Olegário Maciel, assumiu e convocou outra eleição, da qual saíra vencedor Mello Vianna, que convidou Sandoval Soares Azevedo para a 
Secretaria do Interior. Essa reforma se constituiu de quatro decretos, regulamentando três pontos tradicionais nas reformas em Minas: ensino primário - para o qual se previa até programa específico - , ensino normal e o programa a ser implantado nesse curso. A reforma ainda criou a Revista do ensino, ${ }^{39}$ estabelecendo seus objetivos e sua organização editorial. Na verdade, o regulamento de 1924 executava a lei 800, de 1920.

\section{Reforma Francisco Campos: a modernidade do mundo urbano.}

Se no decênio de 1910 a educação popular no Brasil se tornou pauta política e foi posta de lado quando a aristocracia rural assumiu o poder, no decênio seguinte ela reentrou na pauta política, em grande parte por causa da onda de nacionalismo gerada pela Primeira Guerra Mundial: era preciso nacionalizar o país, ameaçado pela infiltração de estrangeiros em razão da guerra; e a criação de uma rede de ensino primário seria uma forma de se alcançar tal objetivo. A campanha pela divulgação da escola elementar apelava ao sentimento nacionalista, pois salientou a necessidade de se recuperar a imagem do Brasil no exterior: país onde havia mais analfabetos no mundo; o analfabetismo era visto então como chaga que impedia o país de pertencer ao grupo de nações cultas e desenvolvidas. Assim, o país tomava consciência da precariedade das instituições escolares - então um dos problemas sociais mais discutidos à época —, e a educação foi vista como única forma de conseguir chegar à democracia.

Se a educação fator-chave do desenvolvimento social, evolução da sociedade, espaço de intercâmbio social, substituta da política, cimento da construção do homem moderno e de uma sociedade orgânica com liberdade, então ela precisava mudar. Nessa lógica, as reformas estaduais do ensino na década de 1920 representaram uma antecipação da transformação do governo quanto a se preocupar com a educação, assim como o delineamento de um sistema em que a importância da educação fundamental resultava do avanço da ordem social burguesa; e aconteceram em vários estados, a exemplo de Minas Gerais.

O governo de Mello Viana terminou em 1926, quando, em 7 de setembro, Antônio Carlos Ribeiro de Andrada, de Barbacena, formado em direito pela Faculdade de Direito de São Paulo e herdeiro de uma carreira política invejável, assumiu a presidência de Minas Gerais. Como era época de efervescência educacional no país, ele surpreendeu a todos com um programa de governo de cunho liberal que rompe com a rotina e em que se destacam iniciativas na área educacional. Dentre os princípios de seu programa de governo, cabe destacar a melhoria e expansão das oportunidades de ensino, pois a educação tinha função estratégica na implantação de governo: a ela cabia oferecer ao indivíduo condições do exercício da cidadania. Como quer Peixoto, a educação tinha esse destaque,

[...] de um lado, pelas próprias condições sócio-econômicas do País naquele momento. Neste novo estágio de desenvolvimento do capitalismo, os problemas relacionados às necessidades de formação de mão-de-obra, à divisão social e técnica do trabalho e a aceleração do processo de urbanização tornam necessária a criação de um sistema de educação comum, capaz de entender as novas exigências no que diz respeito a mão-de-obra capaz de incorporar os novos grupos ao projeto das classes dominantes. ${ }^{40}$

Das ações de Antônio Carlos na área da educação, destacam-se a "[...] fundação da Universidade de Minas Gerais (Lei $\mathrm{n}^{\circ}$ 956, de 7/9/27); a extensão do ensino primário de médio, mediante a construção de uma rede de novos prédios escolares e a aquisição de 
modernos aparelhos e materiais pedagógicos". ${ }^{41}$ A criação da universidade - segunda do Brasil - vinha suprir a necessidade secular. No ensino primário e normal, ele fez uma reforma cujas medidas marcaram uma ação mais intensa pelo estado em relação à sociedade civil.

Para ajudar no planejamento e na implantação de seu programa de governo, Antônio Carlos convocou Francisco Luís da Silva Campos, que assumiu o cargo de secretário do Interior e faria a reforma do ensino público mais importante da década.

Advogado e jurista [que] formou-se pela Faculdade Livre de Direito de Belo Horizonte, em 1914. Em 1919, iniciou sua carreira política elegendo-se deputado estadual em Minas Gerais na legenda do Partido Republicano Mineiro (PRM). Dois anos depois, chegou à Câmara Federal, reelegendo-se em 1924. Em 1926, com a posse de Antônio Carlos no governo de Minas Gerais, assumiu a secretaria do Interior daquele estado. Utilizando-se de muitos postulados defendidos pelo movimento da Escola Nova, promoveu uma profunda reforma educacional em Minas. ${ }^{42}$

As ideias que orientaram a reforma de Francisco Campos representaram uma tomada de posição política e constituiu uma tentativa de responder ao momento histórico vivenciado pela sociedade mineira na década de 1920. Campos era uma das personalidades públicas mais importantes à época, figura exponencial do pensamento educacional tupiniquim e cuja crença era de que, com educação de qualidade, era possível erradicar os males da sociedade civil.

A dupla formada por Antônio Carlos e Francisco Campos propõe então criar

[...] um todo harmonioso, a sociedade democrática. Nesta, o voto secreto constitui expressão máxima da igualdade de direitos e de participação de todos os indivíduos na ordem universal, um símbolo da auto-afirmação individual. Na construção dessa sociedade a educação tem um papel de destaque, uma vez que da escolaridade depende o direito do voto. Além disso, a educação adquire o caráter de instrumento nivelador, capaz de garantir aos indivíduos oportunidades sociais. ${ }^{43}$

Para um e outro, educação era instrumento de reconstrução social. A formação de pessoas racionais, capazes de respeitar e que os direitos inalienáveis de cada um fossem respeitados com base na formação escolar faria surgir uma sociedade harmoniosa fundada na igualdade de direitos. Eis a grande função da escola para Campos: transformar as pessoas em seres racionais, ou seja, adaptá-las adequadamente à sociedade em que vivem. A escola de que tratava Campos não era a escola tal como estava implantada no Estado. Para atuar em sua grande missão transformadora do social, a escola tinha de mudar, de modo a abranger não só o ensino primário, mas também o normal, a fim de que este pudesse capacitar o professor segundo os métodos educacionais mais modernos até então.

Em 15 de outubro de 1927, saiu o decreto $7.970,{ }^{44}$ que oficializou a reforma do ensino primário, técnico-profissional e normal em Minas Gerais almejada por Campos.

A reforma caracterizava os esforços anteriores em termos educativos como sem sucesso, descrevendo como caótico o quadro educacional brasileiro. A falta de materiais, a inconsistência dos métodos, a inadequação das instalações e a ineficiência do ensino clamada pelos altos índices de analfabetismo (em torno de 80\%) eram os argumentos 
recorrentes de educadores e jornalistas na configuração da escola brasileira. ${ }^{45}$

A reforma se preocupava com o aspecto técnico-pedagógico do sistema escolar, mas seu mentor queria, com ela, chegar a uma sociedade liberal de fato. Isso está patente na parte 6 do decreto, nos artigos 195-6:

Art. 195. A escola primária, sendo destinada não somente à instrução, como também à educação, deve procurar desenvolver nos alunos o instituto social, oferecendo-lhes oportunidade de exercer os sentimentos de sociabilidade, responsabilidade e cooperação. Parágrafo único. Para este fim deverá os directores e professores concorrer para a organização de associações escolares e promover obras e estudos escolares feitos em comum, pelotões de saúde e higiene e outras formas de actividade social próprias da infância. Art. 196. Além disso, a escola deve manter-se em íntimas relações com o meio social em que funciona, colaborando com as instituições complementares e auxiliares da escola na obra de aperfeiçoamento do meio escolar e social da localidade, para o que procurará interessar na vida da escola e da população local, particularmente as famílias dos alumnos. ${ }^{46}$

Com efeito, é possível ver que, ao decreto, subjaziam as bases liberalistas da educação. Retomemos brevemente a noção de liberalismo - e sua influência na educação - a fim de evidenciá-las. O liberalismo tem raízes no humanismo, que começou com a contestação da autoridade das igrejas oficiais na Renascença. Mas os movimentos em geral tidos como liberais surgiram durante o Iluminismo e se opunham à monarquia absoluta, ao mercantilismo e a formas diversas de ortodoxia religiosa e clericalismo. Foram os primeiros a formular os conceitos de direitos individuais e do primado da lei, bem como a ressaltar a importância do autogoverno mediante representantes eleitos pelo voto.

$\mathrm{O}$ enfoque na liberdade como direito político essencial das pessoas foi defendido repetidamente ao longo da história. O conceito básico de liberdade é cria da Grécia Antiga. $\mathrm{Na}$ Idade Média, as cidades italianas se revoltaram contra os Estados pontifícios papais debaixo da bandeira da liberdade, e, um século e meio depois, o filósofo Nicolau Machiavel fez da defesa das liberdades civis a chave da forma republicana de governar. A resistência holandesa ao opressivo catolicismo espanhol é com frequência apontado como outro exemplo; mesmo com a recusa em conceder liberdade de culto aos católicos, é em geral considerada uma luta predecessora dos valores liberais.

Como ideologia consistente, em que a liberdade não é acessória mas base dos direitos políticos e, mais tarde, do próprio Estado, o liberalismo é uma corrente política que abrange ideologias históricas diversas e presentes que proclama como único objetivo do governo a preservação da liberdade individual. Tipicamente, o liberalismo favorece o direito à discordância dos credos ortodoxos e das autoridades estabelecidas em termos políticos ou religiosos. Nessa lógica, opõe-se ao conservadorismo. O liberalismo rejeita axiomas fundamentais que dominam vários sistemas anteriores de governos político, tais como direito divino dos reis, hereditariedade e sistema de religião oficial. Seus princípios fundamentais incluem transparência, direitos individuais e civis, em especial o direito à vida, à liberdade, à propriedade, a um governo baseado na liberdade pelo voto, à igualdade da lei e de direitos para todo e qualquer cidadão, que tem o direito de pensar o que quer, exprimir-se e pôr em prática o que pensa da forma como bem quiser - desde que não infrinja diretamente a igual liberdade do outro. O liberalismo parte do princípio de que o 
homem nasce livre e que o papel da sociedade é proporcionar meios para que ele atue na sociedade com liberdade, mas com consciência.

O ápice das concepções liberais ocorreu no século XVIII, quando houve grandes transformações políticas, sociais, econômicas, educacionais e religiosas; quando houve um processo de laicização e de mais liberdade das classes sociais e das pessoas (liberdade de ação e julgamento); enfim, quando se realizou, pela primeira vez, uma "sociedade moderna" em sentido próprio: "[...] burguesa, dinâmica, estruturada em torno de muitos centros (econômico, políticos, culturais, etc.), cada vez mais participativa e inspirada no princípio e valor da liberdade". ${ }^{47}$

As ideologias do liberalismo se desenvolveram em várias instâncias. Não só na economia, na religião e na consciência dos indivíduos civis, o liberalismo surgiu como ideologia política e se desenvolveu, também, na educação. Ora, como em qualquer época, a escola sempre foi "lócus" da divulgação de ideais, por isso incorporou os ideais liberalistas e foi espaço de sua propagação.

[...] no século XVI desenvolve-se uma imagem nova da pedagogia moderna: laica, racional, científica, orientada para valores sociais e civis, crítica em relação a tradições, instituições, crenças e práxis educativas empenhada em reformar a sociedade também na vertente educativa, sobretudo a partir da vertente educativa. ${ }^{48}$

As bases teóricas do liberalismo advieram dos iluministas, que delinearam uma renovação dos fins da educação, dos métodos, depois das instituições. Primeiramente, renovou-se a escola com uma reorganização das bases estatais segundo as finalidades civis, depois se promoveram programas de estudos radicalmente novos e funcionais, para formar o homem moderno: mais livre, mais ativo, mais responsável na sociedade e nutrido do espírito burguês. O liberalismo delineou uma forma nova de educação para a sociedade que influenciou a educação nos séculos seguintes. A escola tem um modelo educacional natural e libertário que busca formar o homem socialmente ativo e responsável. Essa educação devia ser desenvolvida pelo Estado, ou seja, ser uma instrução estatal para todos, civil, laica, gratuita e obrigatória.

Outros sujeitos educacionais surgiram. Um é a criança, não mais vista como "miniatura de homem", e sim como sujeito educacional por excelência, sujeito dos jardins de infância ao lado da escola, pois agora é justamente na idade pré-escolar que se desenvolve o germe da personalidade humana. Outro é a mulher, que começou a se afirmar cada vez mais no centro da cena educacional. Um terceiro exemplo foram pessoas com deficiência física, que começaram a ter seu espaço na educação, isto é, foram postas no centro de uma pedagogia de recuperação que objetivou normalizá-las. Por fim, entrou em jogo na educação a ótica do profissionalismo, que a escola assumiu como tarefa social primária. As bases teóricas liberais vieram, também, de filósofos: “[...] de Locke a Diderot, de Condillac a Rousseau, de Genovesi a Kant, de Basedow a Pestalozzi". ${ }^{49}$ Esse último nos interessa mais aqui, pois é com base em Pestalozzi ${ }^{50}$ que Cambi define essa educação para o trabalho e a questão do liberalismo na educação:

Em Pestalozzi podemos colher o vínculo estreitíssimo entre pedagogia e sociedade através da disciplina e do trabalho, mas também a formação do homem vista como exercício da liberdade e da participação na vida coletiva, econômica e social. É na liberdade que Pestalozzi (como depois Fichte e Froebel) indica a função sociopolítica e portanto ideológica da educação: a ação que deve emancipar integrando, tornando o sujeito 
partícipe e responsável na nova sociedade a caminho, industrial e liberal. ${ }^{51}$

Discípulo de Pestalozzi, o pedagogo Froebel $^{52}$ defendeu a pedagogia libertadora em torno do amor pela infância. Para ele, o professor tem de assumir um comportamento antiautoritário e preservar a espontaneidade e inocência da criança; os jardins de infância têm de ser um espaço não só de recolhimento dos infantes, mas também de aparelhos para o jogo (que ele vê como atividade séria e que desenvolve o espírito humano), para o trabalho infantil e para atividades grupais, organizados por um educador especializado em orientar atividades. Para Froebel, eles têm de ter canteiros e áreas verdes para estimular atividades variadas na criança.

No século XX, os ideais da pedagogia libertadora foram difundidos pela Escola Nova, cujo movimento propunha acabar com a rigidez do ensino escolar tradicional. Acreditava-se que um ensino mais libertador e humanizado formaria cidadãos mais participativos e engajados, numa internacionalização ainda mais precoce de regras de convivência numa sociedade disciplinada, racionalmente distribuída e democrática. A prática educativa no século XX se voltou a um sujeito humano novo: o homem-indivíduo e homem-massa ao mesmo tempo; impôs novos protagonistas (crianças, mulheres, pessoas com deficiência física), renovou instituições formativas (da família à escola e à fabrica etc.), dando vida a um processo de socialização dessas práticas (com envolvimento do poder público sobretudo) e de articulação e sofisticação. A escola se impôs como instituição-chave da sociedade democrática e se nutriu de um forte ideal libertário.

$\mathrm{Na}$ base dessa escola, estavam descobertas da psicologia - a psique infantil difere radicalmente da do adulto - e a emancipação das classes populares - abaixo o papel elitista da escola. Em seu desenvolvimento, o movimento foi acompanhado e sustentado por um trabalho intenso de teorização com base nos fundamentos filosóficos e científicos da renovação pedagógica. O trabalho das escolas novas formou um projeto de educação ativa cujo movimento vinculava a pedagogia às ciências humanas; também reconhecia a importância da criança no processo educacional, valorizava o "fazer" na aprendizagem infantil (atividades manuais, jogos e trabalhos como atividades educativas centrais, motivando a criança com temas que ela propunha como aprendizagem mais significativa), além de apontar o estudo do ambiente como essencial à aprendizagem, incentivar a socialização através de trabalhos em grupos e discriminar o autoritarismo dos professores, propondo uma educação mais livre e com características de amor materno.

Os mestres teóricos do ativismo devem ser reconhecidos em Dewey e Decroly, em Claparède e Ferrière, além de Maria Montessori. Neste estudo, detemo-nos em Decroly e Montessori, por terem sido citados por Francisco Campos no desenvolvimento de sua reforma.

A obra educacional de Decroly ${ }^{53}$ se destaca pelo valor que deu às condições de desenvolvimento infantil, ao caráter global da atividade da criança e à função de globalização do ensino. Promove o trabalho em equipe, mas mantém a individualidade do ensino a fim de se preparar o educando para a vida. A ausência de ideais religiosos caracteriza seu modelo pedagógico, por isso seria liberalista. Decroly postulava que a escola, vista como instituição humana mais elevada, tinha de se modificar profundamente. Sua crítica era severa porque a escola não cumpria seus propósitos; e, para ele, o futuro de um povo dependia da organização e influência da escola, a educação não era uma preparação para a vida adulta e a criança teria de aproveitar sua juventude e resolver dificuldades compatíveis com seu momento de vida. $O$ pressuposto básico era que a necessidade produz interesse, essencial ao conhecimento, pois está na base de toda atividade, incita a criança a observar, associar e a se expressar. 
Ainda na visão de Decroly, as necessidades básicas do homem em sua troca com o meio seriam alimentar-se, defender-se das intempéries, lutar contra perigos e inimigos, trabalhar em sociedade, descansar e se divertir. Desse pressuposto derivou sua proposta de organização escolar. Mais conhecido como centros de interesse, seu método se destinava, em especial, a crianças de classes primárias. Nesses centros, elas passavam por três momentos:

A "observação, que é ponto de partida de todo conhecimento, que deve
ser colocada no centro da atividade escolar, cujo lema deve ser "poucas
palavras, muitos fatos", usando-se um material bastante variado que deve
ser manipulado e observado diretamente pela criança; a "associação", que
organiza, embora de forma elementar, o ambiente que a criança observou
na direção do espaço e do tempo, dando lugar aos conhecimentos
fundamentais da geografia e da história; a "expressão", que pode ser
concreta ou abstrata: a primeira refere-se aos trabalhos manuais, à
modelagem e ao desenho; a segunda, à linguagem, ou seja, à leitura e à
escrita. $^{54}$

Outra página central na história do ativismo foi escrita pela pedagogia montessoriana, ${ }^{55}$ que se vincula à normatização, isto é, à harmonização como interação de forças corporais e espirituais - corpo, inteligência e vontade. O sistema montessoriano está em escolas do mundo todo, e o método objetiva educar a vontade e atenção; nele, a criança tem liberdade de escolher o material a ser usado, além de proporcionar a cooperação. Os princípios fundamentais desse sistema são a atividade, a individualidade e a liberdade; a ênfase nos aspectos biológicos supõe a vida como desenvolvimento, por isso é função da educação favorecer esse desenvolvimento. A criança deve desenvolver livremente suas atividades para amadurecer suas capacidades e atingir um comportamento responsável. Mas tal liberdade - diria Maria Montessori — não pode ser confundida com espontaneidade; antes, tem de acontecer sob vigilância atenta e não opressiva do professor. Nessa lógica, a criança na sala de aula era livre para agir sobre os objetos sujeitos à ação dela, mas estes já estavam preestabelecidos, como os conjuntos de jogos e outros materiais que desenvolveu.

A pedagogia de Montessori se insere no movimento das escolas novas, é uma oposição aos métodos tradicionais que não respeitavam necessidades e mecanismos evolutivos do desenvolvimento da criança. Ocupa papel de destaque nesse movimento pelas técnicas que apresentou aos jardins de infância e às primeiras séries do ensino formal. Montessori criou ainda materiais didáticos para seu trabalho educativo, que pressupõem compreender as coisas partindo-se delas mesmas e tendo como função estimular e desenvolver a criança com um impulso interior que se manifesta no trabalho intelectual espontâneo. Montessori tem o mérito de ter conjugado, com esforço teórico e político notável, o momento da necessidade de uma pesquisa científica com a libertação da criança e do homem, associando com originalidade dois elementos em geral distantes na pedagogia.

Dito isso, Francisco Campos sugeriu em sua reforma exatamente o que os liberalistas/iluministas propunham: reconstruir o aparelhamento do ensino público, o espaço físico e as relações humanas na escola. Por isso, criou associações escolares e favoreceu o espírito associativo infantil, a cooperação e recreação, além de mudar a relação entre aluno e professor - agora o discente teria voz ativa no processo educacional.

A função educacional do Estado e a obrigatoriedade do ensino apareceram na primeira parte do decreto: "Do ensino primário em geral", nos artigos $1^{\circ}, 2^{\circ}$ e 21 : 
Art. $1^{\circ}$. O ensino primário ministrado pelo Estado de Minas Gerais será de duas categorias: o fundamental e o complementar, sendo que o último terá caráter technico-profissional e regulamento à parte. Art. $2^{\circ}$. O ensino fundamental é obrigatório e leigo, e dividi-se em dois graus, correspondendo o primeiro grau às escolas infantis, e o segundo às escolas primárias, cujo curso será de três e quatro anos, respectivamente. [...] Art. $21^{\circ}$. É obrigatória a frequiência das escolas de ensino primário para as creanças de ambos os sexos, dos 7 aos 11 anos de edade. Essa obrigação estende-se ate os 16 anos, em relação aos indivíduos que, aos 14, não estiverem habilitados nas matérias do curso primário. ${ }^{56}$

A laicidade apareceu na parte 15, Art. 580, disposições gerais:

Art. 580. Nos edifícios das escolas públicas e particulares subvencionadas, poderá ser ministrado, fora das horas dos trabalhos escolares, pelo ministro do culto que a isto se propuser, o ensino da religião catholica. Parágrafo único. Esse ensino será facultativo, sem cunho oficial e não será ministrado aos alumnos cujos os paes e responsáveis a ele se opuserem. ${ }^{57}$

Quanto à educação de pessoas com deficiência física, o decreto 7.970 tinha, na parte 11, um subtítulo inteiro destinado ao ensino delas: "Das escolas especiais para débeis orgânicos e para retardos pedagógicos". Segundo os artigos 366-83, as escolas com classes especiais para débeis teriam edifícios próprios e aplicação de testes psicológicos, exames médicos e terapêuticos, além de atividades como escrita, cálculo, desenho, jogos e trabalhos manuais. Também seriam nomeados professoras aptos a esse tipo de ensino. Os jardins de infância idealizados e concretizados por Froebel estavam previstos na parte 7 do decreto, nos artigos 233-45. Sobretudo nessa parte relativa ao jardim de infância há vários fundamentos da escola nova, um dos postulados mais influentes na reforma em busca de técnicas pedagógicas melhores e de mais liberdade para alunos e professores.

Como se vê, a reforma Francisco Campos tinha um discurso de tom liberal e modernizante. Foi o movimento pedagógico mais considerável da história do estado, de repercussão no progresso da educação do país todo. Nitidamente, refletiu aspirações de uma fração da classe dominante da época. É fato que os processos de ensino não mudaram radicalmente sua orientação e seu sentido do dia para noite. A transição e acomodação demoraram. Houve dificuldades e tropeços. Mas esse movimento envolveu grupos empenhados em pôr a educação e a escola a serviço de forças emergentes na sociedade, cuja economia agroexportadora caminhava para se tornar urbano-industrial. Tentavam pôr em prática, portanto, o princípio da ideologia liberal de que a escola é direito de todos.

\section{Considerações Finais}

Política e economicamente, Minas era um pilar da forma republicana de governar, instaurada e dominada por forças econômicas de mais presença na economia vigente desde o Império: a agroexportadora. A política café com leite alijou os aliados de menor poder e se consolidou, embora alguns buscassem outros caminhos rumo à modernização do país, a exemplo de Rui Barbosa, que defendia a industrialização. O estado buscou se adequar aos novos tempos reformando o ensino no início do século XX com João Pinheiro, implantando grupos escolares ${ }^{58}$ por meio dessa mesma reforma e, ainda, aprofundando sua atuação no cenário educacional com a reforma de Francisco Campos (1927-8), coroamento do esforço de renovação da década de 1920. Todavia, o efeito dessas reformas não era imediato, pois demoravam a chegar a muitos municípios mineiros. 
O século XX começou sob os auspícios de reformas educacionais, das quais uma veio implantar " [...] uma instituição educativa comprometida com os ideais republicanos e com as perspectivas de modernização da sociedade brasileira": ${ }^{59}$ os grupos escolares. Todavia, detemo-nos, sobretudo, em duas: a João Pinheiro e a Francisco Campos, de 1906 e 1927, respectivamente. Recorremos a fontes como jornais de época, sobretudo de Uberabinha, trabalhos acadêmicos que investigaram as reformas, Revista do ensino, textos de estudiosos da educação publicados nas primeiras décadas do século XIX, legislação da época e atas das Câmaras Municipais. Cremos que uma leitura crítica dessas fontes pode delinear uma visão de conjunto que facilite compreender a história da educação em Minas e em Uberabinha nos primeiros 30 anos do século passado, assim como entender a relação entre processo educativo e ideia de modernidade.

Das transformações nos dez primeiros anos do século passado, duas suscitaram debates que refletiam preocupações com a educação brasileira na modernidade: aumento da população urbana e crescimento industrial (ainda incipiente). Em parte, dentre os motivos para essa discussão, pode-se supor que um era a incoerência entre tal desenvolvimento - de tendência ascendente - e o analfabetismo no país todo - também ascendente. Como província mais populosa, Minas Gerais não ficou imune à discussão, a ponto de já em 1870 ter uma legislação escolar interessada no ensino primário instrumento de inserção do brasileiro em sua cidadania. Em 1887, o então presidente Carlos Augusto de Oliveira Figueiredo criticou severamente as escolas normais: a escola do professor - espaço de formação de quem ia desenvolver o trabalho no ensino primário. ${ }^{60}$ Para esse presidente, a escola normal não produzia os resultados esperados. Em 1892, um decreto reformou a instrução pública mineira e extinguiu os externatos; conforme a reforma Afonso Pena (lei 41), o programa de ensino devia ser adaptado à região onde estivesse a escola. Em 1899, Francisco Silvano de Almeida Brandão sancionou a lei 281, que organizou e estabeleceu diretrizes para o ensino público em Minas. Em 1901, a lei 318 reformulou o currículo do ensino normal. Em 1906, o presidente Francisco Antônio Salles, via decreto 1.908, definiu a distribuição das cadeiras no curso normal, unificando o currículo em todas as escolas normais.

\section{Referências}

ANDRADA, Antônio Carlos Ribeiro. Dicionário bibliográfico de Minas Gerais período republicano: 1889-1991.

BARBOSA, Rui. Reforma do ensino primário e várias instituições complementares da instrução pública. Rio de Janeiro, Ministério da Educação e Saúde, 1947.

CAMBI, Franco. História da pedagogia. São Paulo: ed. da unesp, 1999.

CHAMON, Magda Lúcia. Relações de gênero e a trajetória de feminização do magistério em Minas Gerais (1830-1930). 1996. Dissertação (Mestrado em Educação) — Faculdade de Educação da Universidade Federal de Minas Gerais, Belo Horizonte.

CUNHA, Fátima. Filosofia da Escola Nova: do ato político ao ato pedagógico. Rio de Janeiro, Tempo Brasileiro; Niterói: Universidade Federal Fluminense/eduff/proed, 1986.

DIÁRIO OFICIAL DE MINAS GERAIS, 16 dez. 1906.

DISCURSO PRONUNCIADO NA ABE, em 19 de novembro de 1925, por Heitor Lyra 
Silva, apud carvalho, 2000.

EM PROL DA INSTRUCÇÃO. O progresso, Uberabinha, anno ii, n. 99, 14 ago. 1909.

FARIA FILHO, Luciano Mendes de; vago, Tarcísio Mauro. A reforma João Pinheiro e a modernidade pedagógica. In: minas gerais, 2000, p. 39 - citação do relatório da Secretaria do Interior ao presidente do estado, 1910.

FAUSTO, Boris. Pequenos ensaios de história da República (1889-1945). In: fenelon, Dea Ribeiro. 50 textos de História do Brasil. São Paulo: Hucitec, 1974.

FUNDAÇÃO GETULIO VARGAS. Centro de Pesquisa e Documentação de História Contemporânea do Brasil. Francisco Campos. Disponível em: <http://cpdoc.fgv.br/producao/dossies/FatosImagens/biografias/francisco_campos>.

Acesso em: 28 mar. 2010.

GRANDE ENCICLOPÉDIA BARSA. 3. ed. São Paulo: Barsa Planeta Internacional Ltda., 2004 p. 294, v. 11.

INSTITUTO BRASILEIRO DE GEOGRAFIA E ESTATÍSTICA/IBGE. Mesorregiões de Minas Gerais, 2001.

MINAS GERAIS. Secretaria da Educação. Decreto 1960, de 16 de dezembro de 1906.

MINAS GERAIS. Secretaria da Educação. Lei 439, de 28 de setembro de 1906.

MINAS GERAIS. Secretaria do interior. Regulamentando da instrução pública.

MINAS GERAIS. Secretaria do Interior. Regulamento ensino primário de Minas Gerais — decreto 7.970 de 15 de outubro de 1927.

MINAS GERAIS. Secretaria do Interior. Regulamento ensino primário de Minas Gerais — decreto 7.970 de 15 de outubro de 1927.

MINAS GERAIS. Secretaria do Interior. Relatório do secretário ao presidente do estado.

MINAS GERAIS. Secretaria do Interior. Relatório do secretário ao presidente do estado, 1909.

MINAS GERAIS. Secretaria do Interior. Relatório do secretário ao presidente do estado.

MINAS GERAIS. Secretaria do Interior. Relatório do secretário ao presidente do estado.

MOACYR, Primitivo. A instrução e o império. São Paulo: Companhia Editora Nacional, 1937.

NUNES, 1998, p. 118 apud gouveia, Maria Cristina Soares de; rosa, Walquíria Miranda. A Escola Normal em Minas Gerais. In: minas gerais. Secretaria de Educação de Minas 
Gerais. Lições de Minas - 70 anos da Secretaria de Educação. Belo Horizonte, 2000, 172p. $7 \mathrm{v}$.

PEIXOTO, Anamaria C. Educação no Brasil — anos 20. São Paulo: Loyola, 1983.

PINHEIRO, João. Minas Gerais, órgão oficial do Estado, 16 dez. 1906.

SECRETARIA DO INTERIOR. Relatório do secretário ao presidente do Estado. 1907, si $2.829,4^{\mathrm{a}}$ seção.

SECRETARIA DO INTERIOR. Relatório do secretário ao presidente do estado. 1909, p. 46. In: minas gerais, 2000, p. 40.

SILVEIRA, Anny Jackeline T. As ruas e as cidades. Cadernos de História, Belo Horizonte: puc/mg, V.2, n. 3, p. 29-35, out. 1997.

SILVEIRA, Anny Jackeline T. Imagens destoantes: a moderna capital de Minas. In: seminário de história da cidade e do urbanismo, 5., out. 1998, Campinas. Anais... Campinas, 1998.

SOARES, Beatriz R. Uberlândia: da Cidade Jardim ao Portal do Cerrado - imagens e representações no Triângulo Mineiro. 1995. Tese (Doutorado em Geografia Humana) Faculdade de Filosofia, Letras e Ciências Humanas da Universidade de São Paulo, São Paulo.

TEIXEIRA, Tito. Bandeirantes e pioneiros do Brasil central. Uberlândia: Uberlândia Gráfica Ltda., 1970.

VARELA, Julia; ALVAREZ-URIA, Fernando. In: minas gerais, 2000.

VIDAL, Diana G. A escola nova e o processo educativo. In: lopes, Eliane M. T.; faria filho, Luciano M.; veiga, Cynthia Greive. 500 anos de educação no Brasil. 2. ed. Belo Horizonte: Autêntica, 2000.

VIEIRA, Flávio C. F; carvalho, Carlos. H. Educação e o movimento de transformação social: Uberabinha (1919-1930). In: congresso de ciências humanas e artes, 5., 2001, Ouro Preto/Mariana. Anais... Universidade Federal de Ouro Preto, p. 2.

ZUIN, Elenice de Souza Lodron. O ensino de geometria e desenho na reforma do ensino primário de Minas Gerais, em 1906. In: lopes, Ana Amélia Borges de Magalhães; gonçalves, Irlen Antônio, faria filho, Luciano Mendes de; xavier, Maria do Carmo (Org.). História da educação em Minas Gerais. Belo Horizonte: fch/fumec, 20.

\footnotetext{
${ }^{1}$ Doutora em Educação pela Universidade de Campinas (UNICAMP). Professora do Programa de PósGraduação em Educação da Universidade de Uberaba (UNIUBE). E-mail: lucianabeatrizcarvalho@yahoo.com.br

${ }^{2}$ MOACYR, Primitivo. A instrução e o império. São Paulo: Companhia Editora Nacional, 1937, p. 221.

${ }^{3}$ CUNHA, Fátima. Filosofia da Escola Nova: do ato político ao ato pedagógico. Rio de Janeiro, Tempo Brasileiro; Niterói: Universidade Federal Fluminense/EDUFF/PROED, 1986, p. 59.

${ }^{4}$ CUNHA, 1986, p. 59
} 
${ }^{5}$ CARVALHO, 2000, p. 55.

${ }^{6}$ Discurso pronunciado na ABE, em 19 de novembro de 1925, por Heitor Lyra Silva, apud CARVALHO, 2000 , p. 150.

${ }^{7}$ CARVAlHo, 2000, p. 56.

${ }^{8}$ CARVALHO, 2000, p. 88.

${ }^{9}$ CARVALHO, 2000, p. 72-3.

${ }^{10}$ CARVALHO, 2000, p. 60; 63.

${ }^{11}$ Personagem criada pelo escritor Monteiro Lobato na obra Urupês que simboliza o atraso, a apatia, a indolência e as doenças do povo brasileiro, muito aquém do povo das nações desenvolvidas.

12 CARVALHO, 2000, p. 141.

13 CARVALHO, 2000, p. 147.

${ }^{14}$ EM prol da instrucção. O progresso, Uberabinha, anno II, n. 99, 14 ago. 1909, p. 1.

${ }^{15}$ CUNHA, 1986, p. 60-1.

${ }^{16}$ João Pinheiro Silva, empresário na cidade de Caeté, foi presidente de Minas em dois períodos: de 11/2 a 23/7/1890; de 7/9/1906 a 25/10/1908, data de sua morte, antes de terminar seu segundo mandato.

${ }^{17}$ VEIGA, 2000, p. 45.

${ }^{18}$ FARIA FILHo, Luciano Mendes de; VAGo, Tarcísio Mauro. A reforma João Pinheiro e a modernidade pedagógica. In: MINAS GERAIS, 2000, p. 39 - citação do relatório da Secretaria do Interior ao presidente do estado, 1910, p. 15; grifo dos autores.

${ }^{19}$ SECRETARIA DO INTERIOR. Relatório do secretário ao presidente do Estado. 1907, Si 2.829, $4^{\text {a }}$ seção. In: MINAS GERAIS, 2000, p. 41.

${ }^{20}$ VEIGA, 2000, p. 38; grifo do autor.

${ }^{21}$ SECRETARIA DO INTERIOR. Relatório do secretário ao presidente do estado. 1909, p. 46. In: MINAS GERAIS, 2000, p. 40.

22 VARELA, Julia; ALVAREZ-URIA, Fernando. In: MINAS GERAIS, 2000, p. 45.

${ }^{23}$ PINHeIRO, João. Minas Gerais, órgão oficial do Estado, 16 dez. 1906, p. 1, cl. 2.

${ }^{24}$ MINAS GERAIS. Secretaria da Educação. Lei 439, de 28 de setembro de 1906, p. 38.

${ }^{25}$ MINAS GERAIS. Secretaria do Interior. Relatório do secretário ao presidente do estado, 1911, p. 26.

${ }^{26}$ MINAS GERAIS. Secretaria do Interior. Relatório do secretário ao presidente do estado, 1909, p. 46.

${ }^{27}$ CHAMON, Magda Lúcia. Relações de gênero e a trajetória de feminização do magistério em Minas Gerais (1830-1930). 1996. Dissertação (Mestrado em Educação) — Faculdade de Educação da Universidade Federal de Minas Gerais, Belo Horizonte, p. 166; grifo do autor.

${ }^{28}$ MINAS GERAIS. Secretaria do Interior. Relatório do secretário ao presidente do estado, 1909, p. 20.

${ }^{29}$ MINAS GERAIS. Secretaria da Educação. Decreto 1960, de 16 de dezembro de 1906, arts. 9, 12 e 13.

${ }^{30}$ CARVALHO, 2000.

${ }^{31}$ MINAS GERAIS. Secretaria do Interior. Relatório do secretário ao presidente do estado, 1907, p. 33.

${ }^{32}$ CHAMON, 1996.

${ }^{33}$ CHAMON, 1996, p. 166; grifo do autor.

${ }^{34}$ MINAS GERAIS. Secretaria do interior. Regulamentando da instrução pública, p. 167; grifo no original.

${ }^{35}$ DIÁRIO OFICIAL DE MINAS GERAIS, 16 dez. 1906, p. 1, cl. 3.

${ }^{36}$ CHAMON, 1996, p. 167.

${ }^{37}$ Vice de João Pinheiro e eleito em janeiro de 1909, Wenceslau Braz Pereira Gomes assumiu o governo em 3 de abril e indicou Estevão Leite de Magalhães Pinto à Secretaria do Interior.

${ }^{38}$ FARIA FILHO; VAGO, 2002, p. 39; grifo do autor.

39 A revista foi criada antes, na primeira reforma do ensino mineiro, no fim do século XIX, governo de Afonso Pena, como informa o parágrafo 18 do artigo 27 da lei 41, de 3 de agosto de 1892 . Nessa etapa, três edições foram publicadas. O regulamento do ensino primário de 1924 a recriou, conforme o título X, que tratava da questão. Nessa nova fase, o primeiro número, sob o encargo da diretoria da Instrução, foi publicado em 8 de março de 1925.

${ }^{40}$ PEIXOTO, 1983, p. 71.

41 ANDRADA, Antônio Carlos Ribeiro. Dicionário bibliográfico de Minas Gerais — período republicano: 1889-1991, p. 34.

42 FUndaÇão Getulio VARgas. Centro de Pesquisa e Documentação de História Contemporânea do Brasil. Francisco Campos. Disponível em:

<http://cpdoc.fgv.br/producao/dossies/FatosImagens/biografias/francisco_campos>. Acesso em: 28 mar. 2010 .

${ }^{43}$ PEIXOTO, 1983, p. 80. 
${ }^{44}$ Com 224 páginas e 586 artigos, divididos em 15 partes, o decreto almejava reconstruir e reformular o ensino em Minas Gerais.

${ }^{45}$ VIDAL, 2005, p. 33.

${ }^{46}$ MINAS GERAIS. Secretaria do Interior. Regulamento ensino primário de Minas Gerais - decreto 7.970 de 15 de outubro de 1927 , p. 103.

${ }^{47}$ CAMB I, Franco. História da pedagogia. São Paulo: ed. da UNESP, 1999, p. 324.

${ }^{48}$ CAMBI, 1999, p. 329.

${ }^{49}$ CAMBI, 1999, p. 330.

50 Johann Heinrich Pestalozzi inovou na educação ao lançar as bases da pedagogia moderna quando concebeu um sistema de ensino prático e flexível que procurava estimular as faculdades intelectuais e físicas da criança. Pestalozzi nasceu em Zurique, Suíça, em 12 de janeiro de 1746. Estudou línguas, teologia, direito e história. Em 1769, comprou uma granja em Neuhof para se dedicar à economia rural e, mais tarde, transformou-a numa escola para crianças pobres. Voltado ao ensino elementar, procurou dar às crianças uma formação profissional, ainda que rudimentar, que lhes permitisse ter uma vida independente e produtiva. A comunidade de Neuhof faliu em 1780, mas Pestalozzi deu continuidade ao seu projeto em Stanz, em 1799, onde enfrentou condições extremamente desfavoráveis ao cuidar de crianças desamparadas pela guerra, e em Burgdorf, entre 1800 e 1804. Em 1805, fundou, em Yeverdon, um instituto que recebia crianças de toda a Europa e funcionava como centro de formação de professores. O instituto adquiriu renome internacional e divulgou suas ideias e seu programa revolucionário de ensino durante vinte anos. O currículo básico enfatizava o entendimento oral e atividades coletivas como desenho, escrita, canto, exercícios físicos, modelagem, cartografia e excursões ao ar livre. O método indutivo criado por Pestalozzi estimulava a observação e o raciocínio pela sucessão de etapas de complexidade gradativamente crescente e dava margem à manifestação das peculiaridades individuais. Pestalozzi foi um dos primeiros educadores a mostrar a influência do meio social na educação. Morreu em Brugg, Suíça, em 17 de fevereiro de 1827. GRANDE ENCICLOPÉDIA BARSA. 3. ed. São Paulo: Barsa Planeta Internacional Ltda., 2004 p. 294, v. 11.

${ }_{51}^{51}$ CAMBI, 1999 , p. 330.

52 Friedrich Wilhelm August Froebel foi adepto das ideias de Pestalozzi, defendeu a liberdade na educação e criou o jardim de infância, instituição adotada no mundo todo. Nasceu em Oberweissbach, Alemanha, em 21 de abril de 1782. Perdeu a mãe aos 9 meses de idade e foi educado pelo pai, pastor protestante. Solitário e introvertido, logo demonstrou grande interesse pela natureza e, aos 15 anos de idade, começou a trabalhar como guarda florestal, enquanto se dedicava ao estudo autodidata de botânica e matemática. Em 1805, tornou-se professor da escola-modelo criada em Frank-Furd por Anton Gruner, que adotava a pedagogia inovadora de Pestalozzi. Ao descobrir sua vocação para o ensino, Froebel viajou para a suíça e colaborou por dois anos com o próprio Pestalozzi, na cidade de Yeverdon. De volta à Alemanha, estudou nas universidades de Göttingen e Berlin, além de começar a desenvolver suas teorias, cujos elementos fundamentais eram os jogos e as atividades livres. Em 1817, criou em Keilhau sua primeira escola, onde pôs em prática suas ideias. Em 1832, fundou o Kindergardem ou jardim de infância; o estabelecimento passou por vários problemas econômicos e acabou sendo fechado pelo governo prussiano. Froebel ainda tentou, sem êxito, continuar seu trabalho em Marienthal, Saxônia, mas morreu em 21 de junho de 1852. GRANDE ENCICLOPÉDIA BARSA, 2004, p. 452, v. 6.

${ }^{53}$ Ovide Decroly foi um dos formuladores da ideia de que era preciso abandonar métodos tradicionais em favor de uma compreensão maior das necessidades da infância. Ele nasceu em Renaix, Bélgica, em 23 de julho de 1871. Doutorou-se em Medicina na universidade de Gand, depois estudou em Berlim e Paris. De volta à Bélgica, especializou-se em neurologia. Dedicou-se ao estudo da infância deficiente e, em 1901, fundou um instituto para a educação de pessoas excepcionais. Em 1907, criou a École d'Ermitage, em Bruxelas, que se tornou famosa como exemplo da "escola nova". Ali, aplicou ao ensino de crianças normais as conclusões extraídas da educação de excepcionais. Desenvolvidas nos livros Vers l'école rénoveé (1921; por uma escola renovada) e Fonction de globalisation (1923; função da globalização), suas concepções fizeram dele um dos renovadores da teoria educacional ao lado de contemporâneos como a italiana Maria Montessori. Seu ponto de partida era que o pensamento infantil não era analítico, mas sintético, ou melhor, sincrético: percebe os objetos em sua totalidade. Nessa teoria, ele baseia seu método de leitura indeovisual, com a integração da ordem perceptiva visual-verbal. Como desdobramento, Decroly formulou o centro dos interesses, baseados nas quatro necessidades fundamentais que, segundo ele, uma criança manifesta: alimentação, vestuário, proteção e recreação. Outra de suas contribuições básicas foi dar um ambiente de liberdade e espontaneidade à escola, que deve ser escola para a vida pela vida. Ele morreu em 10 de setembro de 1932, em Bruxelas. GRANDE ENCICLOPÉDIA BARSA, 2004, p. 85, v. 5.

${ }^{54}$ CAMBI, 1999, p. 528. 
55 Criadora do método de ensino que levou seu nome, Maria Montessori baseou suas concepções pedagógicas na defesa do potencial criativo da criança e no direito de receber uma educação adequada às peculiaridades da personalidade. Ela nasceu em Chiaravalle, próxima a Ancona, Itália, em 31 de agosto de 1870. Primeira mulher a se graduar em medicina (1894) na Itália, logo ingressou como assistente na clinica psiquiátrica da Universidade de Roma, onde começou a se interessar pela educação de crianças portadoras de deficiências mentais. De 1904 a 1908, ocupou a cadeira de antropologia da Universidade de Roma. Em 1907, num bairro pobre de Roma, abriu sua primeira casa dei bambini (casa das crianças), onde aplicou, na educação de meninos normais, a metodologia bem-sucedida no trabalho com crianças portadoras de deficiências mentais. O método montessoriano conjuga o desenvolvimento biológico e mental da criança, dando ênfase ao treinamento prévio dos movimentos musculares necessários à realização de tarefas como a escrita. Ela cria uma nova relação entre aluno e professor, em que este orienta aquele, que por si só se corrige. Em 1922, foi nomeada inspetora do governo nas escolas italianas, mas deixou o país em 1934 por discordar do regime fascista. Morreu em Noordwijkaanzee, Países baixos, em 6 de maio de 1952. GRANDE ENCICLOPÉDIA BARSA, 2004, p. 146, v. 10.

${ }^{56}$ MINAS GERAIS. Secretaria do Interior. Regulamento ensino primário de Minas Gerais - decreto 7.970 de 15 de outubro de 1927 , p. $25 ; 31$

${ }^{57}$ MINAS GERAIS. Secretaria do Interior. Regulamento ensino primário de Minas Gerais - decreto 7.970 de 15 de outubro de 1927 , p. 223.

${ }^{58}$ Grupos escolares podem ser conceituados como escolas graduadas e escolas centrais, termos com o mesmo sentido. No Diccionario de las ciencias de la educación, são um "Sistema de organização vertical de ensino por cursos ou níveis que se sucedem. As características principais da escola graduada são: a) agrupamento dos alunos segundo um critério nivelador que pelo geral é a idade cronológica para obter grupos homogêneos; b) professores designados a cada grau; c) equivalência entre um ano escolar do aluno e um ano de progresso instrutivo; d) determinação prévia dos conteúdos de diferentes matérias para cada grau; e) o aproveitamento do rendimento do aluno é determinado em função do nível estabelecido para o grupo e o nível em que se encontra; f) promoção rígida e inflexível dos alunos grau a grau”. Cf. souZA, 1998, p. 69.

${ }^{59}$ NUNES, 1998, p. 118 apud GOUVEIA, Maria Cristina Soares de; ROS A, Walquíria Miranda. A Escola Normal em Minas Gerais. In: MINAS GERAIS. Secretaria de Educação de Minas Gerais. Lições de Minas 70 anos da Secretaria de Educação. Belo Horizonte, 2000, 172p. 7 v.

${ }^{60}$ ZUIN, Elenice de Souza Lodron. O ensino de geometria e desenho na reforma do ensino primário de Minas Gerais, em 1906. In: LOPES, Ana Amélia Borges de Magalhães; GONÇALVES, Irlen Antônio, FARIA FILHO, Luciano Mendes de; XAVIER, Maria do Carmo (Org.). História da educação em Minas Gerais. Belo Horizonte: FCH/FUMEC, 2002, p. 427-30.

Recebido em fevereiro de 2012

Aprovado em abril de 2012 